matic diseases before they can be dealt with really effectually.

Just as rickets and scurvy could be dealt with from the treatment side before vitamins were thought of, so rheumatism can to some extent be controlled, but we still await the basic thought which will make our control complete and logical. And indeed it does not follow that some specific virus need be discovered to bring this about, for the world famous allegory of the " seed and the soil " may be found to have its most complete vindication in the field of the rheumatic diseases.

Sir Humphrey Rolleston draws a most accurate and readable picture of the history of rheumatism. Hench of the Mayo Clinic discusses whether rheumatoid arthritis is a disease of microbic origin, and quotes 175 references, and concludes rather hesitatingly, that " experience with large numbers of patients has given me the distinct clinical impression that a programme of treatment based on approval of the microbic theory is superior to those programmes which .... relegate it to a place of minor importance." We feel that Dr. Hench could have said nothing which more aptly fits the evidence, and it is a fitting tribute to the pertinacity of mankind that he considered 175 references necessary to justify his conclusion.

Ralph Ghormley states the pathology of non-specific arthritis clearly, and states very truly that only material obtained at operation is likely to be useful in elucidating the disease and that this is comparatively hard to come by.

Copeman very rightly deprecates the attempt to dogmatise about the pre-arthritic stage of rheumatoid arthritis, and says, what badly needs saying, that papers and results published on the treatment of arthritis in the "pre-arthritic" stage should be considered with reserve. There is no doubt that this should be borne in mind by those enthusiasts who are convinced that they are able to recognise a "pre-arthritic" stage clinically, although it should be no deterrent to the recognition of the disease in its very early stages.

The editing of a book of this size, concerned with so many diverse contributors, must of necessity be a big task, but consideration should be given to the fact that its circulation may be large and possibly. world-wide, and every care should be given to this side of the work. There is, therefore, no need to spoil Dr. Bernard Schlesinger's very excellent article on Still's disease by putting in one of the X-ray plates upside down, and there are, besides this, a good many printer's slips in the book, some of which might be misleading to the less initiated.

On the whole, however, the book is excellent, covers the field which it set out to cover adequately and with distinction, and is a fitting memorial for the occasion which it celebrates.

\section{ANATOMY AND PHYSIOLOGY OF PHYSICAL TRAINING.}

By Major R. W. Galloway, D.S.O., M.B., Ch.B., R.A.M.C. Edward Arnold \& Co. 1937. Price 6/-.

In his book on the Anatomy and Physiology of Physical Training Major Galloway has made a praiseworthy attempt to show that the human skeleton is not merely a mass of dry bones and that muscleso are made for movement. Too often is the muscular system looked upon as static ando the importance of function is either forgotten? or made subservient to structure.

The paragraph on postural defects might well have been elaborated, with perhaps a little more stress on synergic action and correlated relaxation, but a useful chapter on the main muscle groups follows (though a misprint of Splenius in the diagram on p. 39 requires correction) and is well capped by a chapter on Corrective Exercises.

Wise words are to be found on p. 62 regarding the use and abuse of the heart muscle, while the value of a good vital capacity is fully stressed. Then follow some valuable hints for the keeping of medical records and detailed methods of carrying out tests, but by far the most interesting part of the book is the small section on research figures.

The influence of smoking on vital capacity and endurance is well brought out and the figures confirming the great advantage of the non-smoker over the smoker are very conclusive. Major Galloway and his collaborator Major Stevenson might have done an even greater service, to athletes in particular, and humanity in general, had they produced experimental evidence of the effects of 
alcohol in a similar set of tests. At a time when so much false information is foisted on the public in the form of highlycoloured advertisements a few clear cold figures would be very illuminating.

The whole book forms a very useful source of information for students of physical training though it unfortunately suffers from the inherent defect of so many text books in not being very readable.

\section{ORTHOPFDIC SURGERY.}

By Walter Mercer, M.B., F.R.C.S.

(Edin.). Edward Arnold \& Co. 1936.

Price 40/-.

The second edition of this well known book contains some 200 more pages and 37 additional illustrations. A great deal of new matter has been introduced and several sections have been entirely re-written.

Written by a general surgeon this book on Orthopædic Surgery gives the view-point of one who has had a general training and this is a distinct advantage. It has become generally recognised that one must first become a good general surgeon before becoming a good specialist. In an age of steadily increasing specialism it is hoped that this dictum will never be lost sight of.

The general plan of the book is excellent, based as it is on lectures and demonstrations given to undergraduates and graduates in surgery reading for a Fellowship in Surgery. The illustrations are clear and a very useful bibliography is given at the end of the book.

Amongst the new subject matter introduced into this edition is a chapter on circulatory disturbances of the extremities. The attention of the orthopædic surgeon is frequently attracted to lesions of the peripheral vessels on account of pain and fatigue in upper and lower extremities. In many cases the real ætiological factor in the causation of this pain is overlooked until a complication such as gangrene supervenes. A reasoned discussion of these affections is therefore welcomed. A clear account is given of sympathectomy in vascular lesions of the extremities together with tests for sympathetic spasm.

A new chapter has been added on manipulative surgery a subject which has been neglected by the medical profession. It is unfortunate that such a valuable therapeutic measure should have fallen so much into the hands of unqualified practitioners. The author discusses the choice of cases for manipulation and the conditions in which it is of value. It is of great importance to choose the right type of case and the author calls attention to the difficulty in deciding upon the indications for manipulative surgery.

This book is highly recommended to students and post-graduates who desire a comprehensive and sound knowledge of orthopædic surgery and the author is to be congratulated on the production of a valuable text-book on the subject.

\section{WHEELER \& JACK'S "HANDBOOK OF MEDICINE." 10th Edition.}

Revised by John Henderson, M.D. E. \& S. Livingstone. Edinburgh. 1937. Price $12 / 6$.

That this "Handbook of Medicine" has earned for itself an assured position is amply revealed by the fact that it has passed through nine editions, as well as having been reprinted on six occasions, since 1903 . We have also no doubt that concise accounts of medicine, such as this proclaims to be, serve a useful purpose, but to be really effective they must be truly concise and specially systematized. To our minds the 10th Edition of "Wheeler and Jack" could be improved in these directions. For one thing the book has now become so large that it cannot conveniently be carried in the pocket, which at one time was one of its greatest assets in the eyes of the student. Any book which runs to 700 pages, unless printed on very special paper, has certainly lost this advantage. We personally feel that with more concise phraseology and a truer perspective (for example chlorosis has two pages devoted to it as against four pages in the case of pernicious anæmia) and with a better classification (the reviser treating laryngismus stridulus and tetany separately and under different systems and divorcing Sydenham's chorea from the other manifestations of the rheumatic infection) much valuable space could have been saved and at the same time a more comprehensive review supplied. We also feel that much concerning physical examination of the various systems could have been omitted for the same reason. 